\title{
Effect of Lactobacillus delbrueckii on cholesterol metabolism in germ-free mice and on atherogenesis in apolipoprotein E knock-out mice
}

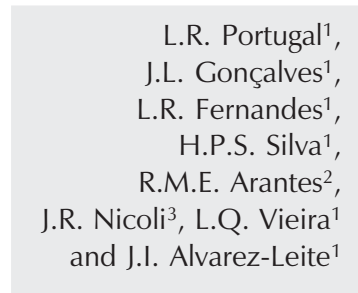

\author{
${ }^{1}$ Departamento de Bioquímica e Imunologia, \\ ${ }^{2}$ Departamento de Patologia Geral, ${ }^{3}$ Departamento de Microbiogia, \\ Instituto de Ciências Biológicas, Universidade Federal de Minas Gerais, \\ Belo Horizonte, MG, Brasil
}

\section{Correspondence \\ J.I. Alvarez-Leite \\ Laboratório de Bioquímica \\ Nutricional \\ Departamento de Bioquímica e \\ Imunologia, ICB, UFMG \\ Caixa Postal 486 \\ 30161-970 Belo Horizonte, MG \\ Brasil \\ Fax: +55-31-3499-2614 \\ E-mail: alvarez@ufmg.br \\ Research supported by FAPEMIG (Orc CBB2818/97). L.Q. Vieira, \\ J.R. Nicoli, J.L. Gonçalves, L.R. \\ Fernandes, and J.I. Alvarez-Leite are recipients of CNPq fellowships. H.P.S. Silva is the recipient of a PROBIC/FAPEMIG fellowship. L.R. Portugal is the recipient of a CAPES fellowship.}

Received May 19, 2005 Accepted November 18, 2005

\begin{abstract}
Elevated blood cholesterol is an important risk factor associated with atherosclerosis and coronary heart disease. Several studies have reported a decrease in serum cholesterol during the consumption of large doses of fermented dairy products or lactobacillus strains. The proposed mechanism for this effect is the removal or assimilation of intestinal cholesterol by the bacteria, reducing cholesterol absorption. Although this effect was demonstrated in vitro, its relevance in vivo is still controversial. Furthermore, few studies have investigated the role of lactobacilli in atherogenesis. The aim of the present study was to determine the effect of Lactobacillus delbrueckii on cholesterol metabolism in germ-free mice and the possible hypocholesterolemic and antiatherogenic action of these bacteria using atherosclerosis-prone apolipoprotein E (apo E) knock-out (KO) mice. For this purpose, Swiss/NIH germ-free mice were monoassociated with $L$. delbrueckii and fed a hypercholesterolemic diet for four weeks. In addition, apo $\mathrm{E}$ KO mice were fed a normal chow diet and treated with $L$. delbrueckii for 6 weeks. There was a reduction in cholesterol excretion in germfree mice, which was not associated with changes in blood or liver cholesterol concentration. In apo E KO mice, no effect of L. delbrueckii was detected in blood, liver or fecal cholesterol. The atherosclerotic lesion in the aorta was also similar in mice receiving or not these bacteria. In conclusion, these results suggest that, although $L$. delbrueckii treatment was able to reduce cholesterol excretion in germ-free mice, no hypocholesterolemic or antiatherogenic effect was observed in apo E KO mice.
\end{abstract}

Key words - Lactobacillus

- Atherosclerosis

- Apolipoprotein E

- Cholesterol

- Germ-free mice 


\section{Introduction}

Elevated serum cholesterol is an important risk factor associated with atherosclerosis and coronary heart disease. Ingestion of probiotics such as lactic acid bacteria is a potential natural method to treat and prevent hypercholesterolemia.

Several studies (1-8) have reported a decrease in serum cholesterol during the consumption of lactic bacteria such as Lactobacillus acidophilus and $L$. reuteri and their fermented dairy products. However, these results cannot be extrapolated to the conditions of human consumption.

The cholesterol-lowering potential of L. acidophilus has been extensively studied in humans. Massey (9) showed that, initially, yogurt consumption significantly reduced cholesterol by 10 to $12 \%$ in human adult males, but 2 weeks later concentrations returned to the control values even with continued yogurt consumption. Lin et al. (10) conducted a large double-blind, placebo-controlled trial with a crossover design on 334 volunteers. The results did not show a significant effect of lactobacilli on serum cholesterol. de Roos et al. (11) found no effect of the consumption of yogurt enriched with $L$. acidophilus L-1 at a dose of $10^{10}$ colony-forming units/day (CFU/day) in a placebo-controlled study of 78 healthy men and women. Thus, the effects of lactobacilli on blood cholesterol are not consistent.

The present study investigated the effect of $L$. delbrueckii on total blood cholesterol and total lipids and on cholesterol in liver and feces in germ-free mice fed a hypercholesterolemic diet. In addition, we investigated the effect of $L$. delbrueckii on cholesterol metabolism, on the lipoprotein fractions and atherosclerotic lesions of the aorta in apolipoprotein E (apo E) knock-out (KO) mice that spontaneously develop hypercholesterolemia and atherosclerosis.

\section{Material and Methods}

\section{Animals and diet}

Thirty-one 8-week-old germ-free mice fed a hypercholesterolemic diet ( $1 \%$ cholesterol and $0.5 \%$ cholic acid) were divided into three groups: control group $(\mathrm{N}=10)$ kept in the axenic condition, EL group $(\mathrm{N}=13)$ simultaneously receiving Escherichia coli EMO and L. delbrueckii in a mixture of De Man, Rogosa and Sharpe (MRS) and brain heart infusion (BHI) culture broth containing $10^{12} \mathrm{CFU} / \mathrm{mL}$ of both bacteria, and $\mathrm{Ec}$ group $(\mathrm{N}=8)$ receiving $10^{12} \mathrm{CFU} / \mathrm{mL}$ E. coli EMO (as a control of colonization with a bacterial strain with no hypocholesterolemic effect). The animals were kept in Trexler type isolators (Standard Safety Company, McHenry, IL, USA) in rooms on a 12-h light-dark cycle and constant temperature $\left(22^{\circ} \mathrm{C}\right)$. The animals had free access to sterile diet and water. After confirmation of cell viability, culture broth was introduced aseptically in the isolators and given orally to the mice separately or mixed with water and food. The experimental diet was introduced only after confirmation of intestinal colonization by feces culture. All animals were sacrificed under anesthesia after 4 weeks of the experiment.

To investigate atherosclerosis development, 4-week-old apo E KO mice with similar body weight (about $17 \mathrm{~g}$ ) and serum cholesterol concentrations (about $300 \mathrm{mg} /$ dL) were used. Since these animals spontaneously develop hypercholesterolemia and atherosclerosis, they received commercial diet (Nuvital, Curitiba, PR, Brazil) ad libitum during the 6 weeks of the experiment. Body weight and food intake were measured weekly. The animals were divided into a control group $(\mathrm{N}=7)$ receiving water and a Lac group $(\mathrm{N}=7)$ receiving saline solution containing L. delbrueckii $\left(10^{12} \mathrm{CFU} / \mathrm{mL}\right)$.

All animals received humane care as outlined in the Guide for the Care and Use of 
Laboratory Animals of the National Research Council (12).

\section{Bacteria}

L. delbrueckii UFV H2B20 and E. coli EMO were isolated and identified at the Federal University of Viçosa (MG, Brazil) and in the Laboratory of Microbial Ecology (INRA, Jouy-en-Josas, France), respectively. The strains were inoculated respectively into MRS and BHI culture media and incubated at $37^{\circ} \mathrm{C}$ for $18 \mathrm{~h}$ before inoculation.

Blood, liver and feces samples. Serum lipoproteins were separated by fast protein liquid chromatography (FPLC) as previously described (13). The liver was removed, washed in saline solution, dried on filter paper, weighed, and frozen at $-20^{\circ} \mathrm{C}$. Feces from the last experimental day were collected, homogenized and frozen at $-20^{\circ} \mathrm{C}$. The hepatic and fecal lipids were extracted as described (14). Total blood cholesterol and cholesterol in FPLC fractions and in hepatic and fecal extracts were determined using commercial kits (KATAL, Belo Horizonte, MG, Brazil)

Histological analysis. The heart and proximal section of the aorta of apo $\mathrm{E} \mathrm{KO}$ mice were removed and cleaned of adventitial tissue. The top half of the hearts was obtained under stereoscopic observation and fixed by immersion in $4 \%$ paraformaldehyde in $0.1 \mathrm{M}$ phosphate-buffered saline at room temperature. The specimens were routinely processed for paraffin embedding and analyzed by the method of Paigen et al. (15) with modifications, as briefly described below. Ten-micrometer thick cross-sections were cut with a microtome (Spencer, \#820, Buffalo, NY, USA) all along the aortic root area $(300 \mu \mathrm{m})$, stained with hematoxylineosin, coded and examined by a single pathologist, who was unaware of the experimental conditions for each group. The slides were decoded only after the report had been written. The aortic root area was recognized by the proximal presence of aortic valve leaflets. One of every three sections (for a total of ten sections per mouse) was kept for morphometric analysis and the images obtained from a microscope coupled to a digital camera were processed with an image analyzer (Kontron Electronic 300 software, Fremont, CA, USA). The total lesion area of each animal was the sum of lesion areas obtained from the ten selected sections. Data are reported as mean total lesion area per group of 7 control and 7 Lactobacillus-treated animals.

\section{Statistical analysis}

Student $t$-test was used to compare control and experimental groups, with the level of significance set at $\mathrm{P}<0.05$.

\section{Results}

\section{Germ-free mice}

To examine the effect of $L$. delbrueckii on cholesterol absorption and metabolism, germ-free mice or germ-free mice colonized with E. coli EMO (without a hypocholesterolemic effect) or E. coli plus $L$. delbrueckii were fed a hypercholesterolemic diet for 4 weeks. Feces culture confirmed the axenic status of control animals, the monoassociation in the Ec group and the diassociation in the EL group until the end of experiment.

Body weight was similar in both groups, suggesting no differences in food intake or nutritional alterations caused by bacterial colonization (data not shown).

At the end of the experiment, no differences in blood cholesterol were observed between groups. The means \pm SEM of control $(\mathrm{N}=10), \mathrm{Ec}(\mathrm{N}=8)$ and $\mathrm{EL}(\mathrm{N}=13)$ groups were $188 \pm 13,163 \pm 13$ and $193 \pm 17$ $\mathrm{mg} / \mathrm{dL}$, respectively. In the liver, total lipids were reduced in the EL group compared to the Ec group and reduced in both when compared to the control axenic group 
(Table 1). However, although the liver cholesterol level was lower in both colonized groups than in the control group, there was no difference between the Ec and EL groups, suggesting an effect of colonization but not specifically of $L$. delbrueckii on liver cholesterol. These results suggest that, although it had no effect on blood cholesterol, $L$. delbrueckii may be able to reduce the absorption or increase the release of lipids from the systemic circulation.

A hypercholesterolemic diet can contaminate the feces and consequently cause an overestimation of the fecal lipid and cholesterol concentration. For this reason, we analyzed lipids and cholesterol in cecum contents. No differences were observed in the concentration of cecal lipids among groups (Table 1). However, the EL group showed a reduction of cecal cholesterol concentration compared to the Ec group $(\mathrm{P}=0.047)$.

Table 1. Total lipids and cholesterol in liver and cecum of NIH mice colonized with Escherichia coli or E. coli and Lactobacillus delbrueckii for 4 weeks or maintained axenic (control).

\begin{tabular}{lccc}
\hline & $\begin{array}{c}\text { Control } \\
(\mathrm{N}=10)\end{array}$ & $\begin{array}{c}\text { E. coli } \\
(\mathrm{N}=8)\end{array}$ & $\begin{array}{c}\text { E. coli }+ \text { L. delbrueckii } \\
(\mathrm{N}=13)\end{array}$ \\
\hline Liver lipids & $322.0 \pm 4.16^{\mathrm{a}}$ & $194.2 \pm 21.81^{\mathrm{b}}$ & $105.3 \pm 5.01^{\mathrm{c}}$ \\
Liver cholesterol & $24.4 \pm 2.5^{\mathrm{a}}$ & $9.6 \pm 0.8^{\mathrm{b}}$ & $8.1 \pm 1.91^{\mathrm{b}}$ \\
Cecum lipids & $\mathrm{ND}$ & $20.0 \pm 4.08$ & $16.6 \pm 0.55$ \\
Cecum cholesterol & $\mathrm{ND}$ & $2.4 \pm 0.22^{\mathrm{a}}$ & $1.9 \pm 0.14^{\mathrm{b}}$ \\
\hline
\end{tabular}

Data are reported as mean \pm SEM in $\mathrm{mg} / \mathrm{g}$. ND $=$ not determined. Different letters on the same line indicate statistically significant differences $(P<0.05$, Student $t$-test).

Table 2. Hepatic and fecal total lipid and cholesterol of apolipoprotein $E$ knock-out mice receiving Lactobacillus delbrueckii for 6 weeks ( $N=7$ mice/group).

\begin{tabular}{lccccc}
\hline Parameter & \multicolumn{2}{c}{ Liver } & & \multicolumn{2}{c}{ Feces } \\
\cline { 2 - 3 } \cline { 5 - 6 } & Control & L. delbrueckii & & Control & L. delbrueckii \\
\hline Total lipid & $112 \pm 9.2$ & $96 \pm 6.8$ & & $30 \pm 13.9$ & $30 \pm 10.1$ \\
Cholesterol & $4.1 \pm 0.2$ & $4.1 \pm 0.2$ & & $4.1 \pm 0.2$ & $3.8 \pm 0.5$ \\
\hline
\end{tabular}

Data are reported as mean $\pm \mathrm{SEM}$ in $\mathrm{mg} / \mathrm{g}$. The controls received vehicle. There were no statistical differences between control and $L$. delbrueckii-treated mice (Student $t$ test).

\section{Apolipoprotein E knock-out mice}

As germ-free Swiss/NIH mice do not develop spontaneous atherosclerosis, we studied the effect of $L$. delbrueckii in a model of atherosclerosis. Apo E KO animals fed on a regular chow diet develop spontaneous hypercholesterolemia and aortic atherosclerotic lesions after the age of 8 weeks. In this experiment, the animals received $L$. delbrueckii daily to maintain the intestinal colonization.

There was no difference between groups when food and water intake and body weight were analyzed (data not shown).

Liver lipids and cholesterol were unchanged after lactobacillus supplementation (Table 2). Similarly, fecal lipids and 3- $\alpha-$ hydroxy sterols (as indicators of cholesterol excretion) were also similar when the Lac group was compared to control animals, suggesting that $L$. delbrueckii has no effect on cholesterol absorption and metabolism under these experimental conditions.

As expected, blood cholesterol was higher than in wild-type animals (about $80 \mathrm{mg} / \mathrm{dL}$ ), confirming the spontaneous hypercholesterolemia occurring in these animals. However, no statistically significant differences were seen between groups at the beginning (300 $\mathrm{mg} / \mathrm{dL}$ for both groups) or after 6 weeks of the experiment $(356 \pm 26$ and $399 \pm 35 \mathrm{mg} / \mathrm{dL}$ for control and L. delbrueckii-supplemented groups, respectively). These results demonstrate, as observed in germ-free mice, no hypocholesterolemic effect of $L$. delbrueckii. Likewise, lipoprotein analysis showed a similar profile of atherogenic (VLDL + IDL + LDL) fractions and also of the protective (HDL) fraction for the various groups (Figure 1).

We then analyzed atherosclerotic lesions in the aorta of mice from both groups. When the aortic valve was analyzed, no reduction in lesion area was observed in mice from the Lac group $\left(278 \pm 76 \times 1000 \mu \mathrm{m}^{2}\right)$ compared to control $\left(199 \pm 95 \times 1000 \mu \mathrm{m}^{2}\right)$. The atherosclerotic lesions in mice of both groups showed an initial lesion (fatty streak) com- 
posed of well-defined foam cells and sparse inflammatory cells (Figure 2). Since there was no difference in blood cholesterol or in atherosclerotic lesions between groups, it was concluded that $L$. delbrueckii does not have a positive effect in preventing atherosclerotic lesions under these experimental conditions.

\section{Discussion}

We investigated the effect of $L$. delbrueckii on cholesterol metabolism in two different models. In germ-free mice fed a hypercholesterolemic diet, we studied the specific effects of this bacterium on cholesterol absorption and liver and blood cholesterol concentrations without the interference of indigenous microbiota. However, wild-type (conventional or germ-free) mice are not the best models to study atherogenesis, since they do not develop atherosclerosis because of their high levels of the protective lipoprotein fraction (HDL). On the other hand, apo E KO mice are good models to study atherosclerosis, since their profile of blood cholesterol and lipoprotein fractions as well as atherosclerotic lesions are closely similar to the human (16). For this reason, we used apo E KO mice to study the influence of $L$. delbrueckii specifically on atherogenesis. Our results showed that colonization by $L$. delbrueckii did not reduce blood cholesterol in germ-free mice, although a reduction of cholesterol excretion was seen in monoassociated animals. The reduction of fecal excretion may indicate a higher intestinal absorption or assimilation of cholesterol by bacteria. As the liver and blood cholesterol concentration was not increased in our experiment, it is probable that $L$. delbrueckii assimilated cholesterol in the intestines.

It has been reported that cholesterol can be removed from culture media by precipitation with free bile acids because of the activity of the bacterial enzyme bile salt hydrolase (17). Enhanced bile salt hydrolase activity in vivo may increase cholesterol excretion. However, this hypothesis was not confirmed by our in vivo experiment since there was a reduction of cecal cholesterol excretion. Several in vitro studies have shown that some bacteria such as lactobacilli assimilate cholesterol from culture media (18-20). This indicates that certain strains could act directly on cholesterol in the gastrointestinal tract, assimilating it from the
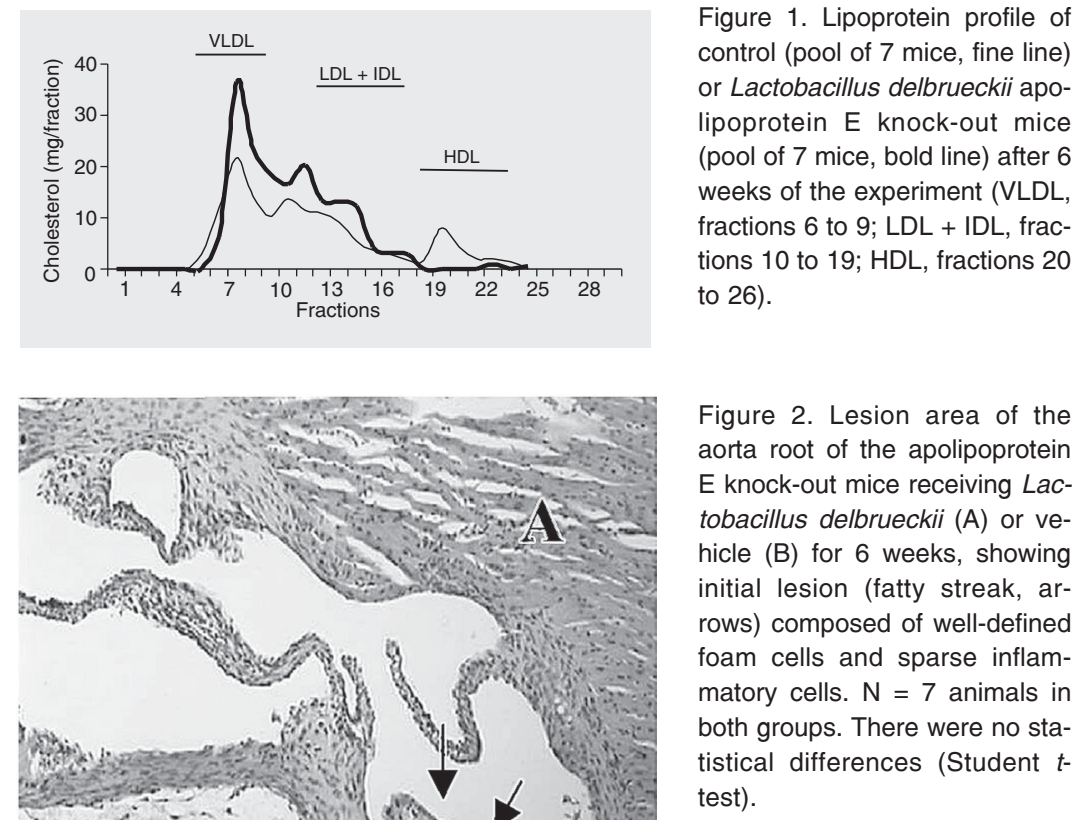

Figure 1. Lipoprotein profile of control (pool of 7 mice, fine line) or Lactobacillus delbrueckii apolipoprotein $E$ knock-out mice (pool of 7 mice, bold line) after 6 weeks of the experiment (VLDL, fractions 6 to 9 ; $L D L+I D L$, fractions 10 to 19 ; HDL, fractions 20 to 26$)$.

Figure 2. Lesion area of the arta root of the apolipoprotein mice receiving $L a c-$ ell-defined sparse inflamtistical differences (Student $t$ test). 
intestines and this could be associated with a reduction in blood cholesterol levels. This mechanism is consistent with our results showing a reduction of cholesterol excretion in EL animals. However, in our experiment this effect was not associated with lower blood cholesterol levels.

It is well known that hepatic cholesterol concentration depends on liver uptake of lipoproteins (via LDL and LRP receptors), cholesterol synthesis (via HMG CoA reductase activity), and bile acid synthesis (via cholesterol 7- $\alpha$-hydroxylase activity). We believe that after 4 weeks the reduction of exogenous cholesterol following L. delbrueckii cholesterol assimilation was compensated mostly by a higher hepatic cholesterogenesis that kept liver cholesterol at levels similar to those of the control group, preventing a reduction of blood cholesterol.

Zacconi et al. (21) investigated the effect of $L$. acidophilus $\mathrm{N} 5$ in axenic mice and in conventionalized flora. Lactobacillus induced a discrete decrease of blood cholesterol in axenic mice, but had no effect in conventionalized mice. The discrepancy between this result and ours may be due to the different species of lactobacillus used in each experiment ( $L$. acidophilus and L. delbrueckii, respectively).

Despite the large number of studies associating lactobacilli and blood cholesterol, there are no studies addressing the effect of these bacteria on atherogenesis. For this reason, we investigated the effect of L. delbrueckii in apo $\mathrm{E} \mathrm{KO}$ mice that spontaneously develop atherosclerosis. To the best of our knowledge, this is the first study directly correlating Lactobacillus inoculation and the development of atherosclerosis.

Contrary to the results obtained for germfree mice, we did not detect differences in fecal cholesterol excretion in apo E KO mice. This may be due to the differences between mouse strains and diets: germ-free mice fed a hypercholesterolemic diet have a higher concentration of cholesterol in the intestines compared to apo E KO mice fed a regular chow diet. Moreover, germ-free mice were diassociated (E. coli and L. delbrueckii) while "conventional" apo E KO mice had an indigenous microbiota. Consequently, in germfree mice, the effect of cholesterol assimilation could be more evident due to the higher cholesterol concentration in the diet and could be detected as a reduction of fecal excretion. In apo E mice, the lower intestinal concentration of cholesterol and the presence of other cholesterol-metabolizing bacterial strains possibly masked the effect of $L$. delbrueckii observed with germ-free mice.

Our main finding was that $L$. delbrueckii did not affect the lipoprotein profile or the development of aortic lesion. We directly showed that the atherosclerotic lesions of $L$. delbrueckii-colonized animals were qualitatively and quantitatively similar to those of control mice. It is possible that other lactobacillus strains have a more potent effect on cholesterol metabolism (or on other components of plaque development) and would be able to impair atherosclerosis formation. For this reason, more studies on bacterial inoculation and atherosclerotic lesions should be performed.

In conclusion, we believe that $L$. delbrueckii can assimilate intestinal cholesterol, but this effect did not impair atherogenesis in apo E KO mice. Since experimental models of atherosclerosis are available, the study of the hypocholesterolemic effect of probiotic bacteria should be performed in these models to determine both the prevention of risk factors and the reduction of atherosclerosis.

\section{Acknowledgments}

We are indebted to Antonio Vaz Mesquita and Maria Helena Alves for excellent care of the germ-free and apo E knock-out mouse colonies, respectively. We also thank KATAL for the donation of cholesterol and HDL kits used in this study, and FAPEMIG, CAPES and $\mathrm{CNPq}$ for financial support. 


\section{References}

1. Mann GV (1974). Studies of a surfactant and cholesteremia in the Maasai. American Journal of Clinical Nutrition, 27: 464-469.

2. McNamara DJ, Lowell AM \& Sabb JE (1989). Effect of yogurt intake on plasma lipid and lipoprotein levels in normolipidemic males. Atherosclerosis, 79: 167-171.

3. Rao DR, Chawan CB \& Pulusani SR (1981). Influence of milk and thermophilus milk on plasma cholesterol levels and hepatic cholesterogenesis in rats. Journal of Food Science, 46: 1339-1341.

4. De Rodas BZ, Gilliland SE \& Maxwell CV (1996). Hypocholesterolemic action of Lactobacillus acidophilus ATCC 43121 and calcium in swine with hypercholesterolemia induced by diet. Journal of Dairy Science, 79: 2121-2128.

5. Akalin AS, Gonc S \& Duzel S (1997). Influence of yogurt and acidophilus yogurt on serum cholesterol levels in mice. Journal of Dairy Science, 80: 2721-2725.

6. Fukushima M \& Nakano M (1996). Effects of a mixture of organisms, Lactobacillus acidophilus or Streptococcus faecalis on cholesterol metabolism in rats fed on a fat- and cholesterol-enriched diet. British Journal of Nutrition, 76: 857-867.

7. Taranto MP, Medici M, Perdigon G et al. (2000). Effect of Lactobacillus reuteri on the prevention of hypercholesterolemia in mice. Journal of Dairy Science, 83: 401-403.

8. Taranto MP, Medici M, Perdigon G et al. (1998). Evidence for hypocholesterolemic effect of Lactobacillus reuteri in hypercholesterolemic mice. Journal of Dairy Science, 81: 2336-2340.

9. Massey $L$ (1984). Effect of changing milk and yogurt consumption on human nutrient intake and serum lipoprotein. Journal of Dairy Science, 67: 255-262.

10. Lin SY, Ayres JW, Winkler Jr W et al. (1989). Lactobacillus effects on cholesterol: in vitro and in vivo results. Journal of Dairy Science, 72: 2885-2899.

11. de Roos NM, Schouten G \& Katan MB (1999). Yogurt enriched with Lactobacillus acidophilus does not lower blood lipids in healthy men and women with normal to borderline high serum cholesterol levels.
European Journal of Clinical Nutrition, 53: 277-280.

12. National Research Council (1996). Guide for the Care and Use of Laboratory Animals. National Research Council, Washington, DC, USA.

13. Peluzio MC, Miguel Jr E, Drumond TC et al. (2003). Monocyte chemoattractant protein-1 involvement in the alpha-tocopherol-induced reduction of atherosclerosis lesions in apo $\mathrm{E}$ knock out mice. British Journal of Nutrition, 90: 3-11.

14. Oliveira DR, Portugal LR, Cara DC et al. (2001). Gelatin intake increases the atheroma formation in apo $\mathrm{E}$ knock out mice. Atherosclerosis, 154: 71-77.

15. Paigen B, Morrow A, Holmes PA et al. (1987). Quantitative assessment of atherosclerosis lesions in mice. Atherosclerosis, 68: 231240.

16. Nakashima Y, Plump S, Raines W et al. (1994). Apo E-deficient mice develop lesions of all phases of atherosclerosis throughout the arterial tree. Arteriosclerosis and Thrombosis, 14: 133-140.

17. Klaver FA \& van der Meer R (1993). The assumed assimilation of cholesterol by Lactobacilli and Bifidobacterium bifidum is due to their bile salt-deconjugating activity. Applied and Environmental Microbiology, 59: 1120-1124.

18. Gilliland SE (1990). Health and nutritional benefits from lactic acid bacteria. FEMS Microbiology Reviews, 7: 175-188.

19. Gilliland SE, Nelson CR \& Maxwell C (1985). Assimilation of cholesterol by Lactobacillus acidophilus. Applied and Environmental Microbiology, 49: 377-381.

20. Gilliland SE \& Walker DK (1990). Factors to consider when selecting a culture of Lactobacillus acidophilus as a dietary adjunct to produce a hypocholesterolemic effect in humans. Journal of Dairy Science, 73: 905-911.

21. Zacconi C, Bottazzi V, Rebecchi A et al. (1992). Serum cholesterol levels in axenic mice colonized with Enterococcus faecium and Lactobacillus acidophilus. Microbiologica, 15: 413-417. 